\title{
Resource use peak dates distract from real planetary limits
}

\author{
Jane N. O'Sullivan $^{1}$
}

Key Words: limits to growth; peak-rate year; synchrony

Seppelt et al.'s (2014) paper "Synchronized peak-rate years of global resources use" has been widely reported in the media. Nature Research Highlights (2015) reported "The rates at which humans consume multiple resources such as food and wood peaked at roughly the same time, around 2006. This means that resources could be simultaneously depleted, so achieving sustainability might be more challenging than was thought."

However, does the paper tell us anything useful about scarcity or sustainability? I suggest that it does not.

Although some of the media coverage may have extrapolated beyond the paper's intent, the Nature report accurately summarizes the emphasis of the paper, and was recommended to me by the paper's lead author. In relation to these key points,

1. In most instances, it was not the rates at which humans use multiple resources that peaked, but the rate of acceleration of those rates of use. Although the paper makes this explicit, its discussion tends to blur the distinction.

2. The "peaks" were not necessarily the highest rate that will ever be achieved, but merely the highest to date. The paper states " 21 resources [of 27 tested] experienced a peak-rate year," presenting these as high-water marks for all time. However, the time series presented for many of the resources show multiple inflection points (peaks in the rate of change). There is no discussion of the impact of this on the methodology, which is designed to identify a single inflection point. (The presence of multiple peaks appears to have been interpreted as a broad probability distribution for the estimation of the presumed single peak.)

3. The peaks were not clustered around 2006. A perusal of Table 3 of the paper would confirm this. In Figure 4, the 5000 separate estimates of the mode of peak-years, repeatedly estimated under a bootstrap analysis, consistently fell around 2006. Regardless of how widely the actual peaks were spread in time, they have only one mode. The tightness of estimation of their mode depends only on the consistency of estimation of each peak year. However, the authors undertook this analysis "to test the hypothesis of synchrony" and presented this figure as showing that "synchrony of the peak-rate years is evident."

A major point of confusion stemmed from the definition of peakrate year inconsistently referring to either the first or second derivative of the cumulative supply. In general, it is applying the first derivative for nonrenewables (except land), but the second for renewables (and land). That is to say, for mined resources, it is reporting the peak in the actual annual "harvest" (increment in cumulative amount), whereas for agricultural commodities it is reporting the peak in the rate of increase of the annual harvest.

The authors justify this distinction because nonrenewables are not replenished so total cumulative consumption is relevant (relative to the maximum retrievable quantity), whereas for renewables the yearly production is more relevant (relative to the maximum sustainable production). In both cases, we can agree that the finiteness of supply is real, and is a legitimate concern for future well-being. However, in relation to scarcity or the sustainability of human systems, it is the annual delivery per capita that matters, whether renewable or not. The nonrenewable nature of mined resources certainly leads to different treatment of future projections of supply, but does not justify the treatment of first and second derivatives of the cumulative amount as being equivalent either mathematically or socioeconomically.

The confusion between values and their derivatives is evident in the paper's statement "the peak rate of earth surface conversion to cropland occurred in 1950 (1920-1960), and the expansion of cropland recently stabilized at the highest recorded levels." It appears to self-contradict by saying that conversion to cropland peaked sixty years ago and that it is currently proceeding at the fastest rate ever. This is like saying your income peaked in the week you got your first full-time pay cheque, although you're currently earning more than ever. The peak rate was merely the biggest step-change. Does this tell you anything about your ultimate wealth?

To be accurate, the statement would have to say that the rate of acceleration of land conversion to cropland peaked in 1950, but the rate of conversion itself kept climbing, although it has recently leveled off and may be nearing a peak. The peak use of land for cropping would be the year when net conversion to cropland had declined to zero. Given the loss of cropland to soil degradation and urban encroachment, this is a real prospect and a serious challenge while global population continues to grow. However, it is not reflected in the second derivative of the time series of area cropped, which is what the paper offers us.

The term "peak" implies a subsequent inexorable decline. The highest growth-rate to date does not prove that a higher rate will not be achieved in the future. If the propensity for relatively recent peak-rate years means anything, it may mean that, overall, production of many renewable resources is still accelerating, but not in a perfectly smooth way. In the same way, continuing climate 
change means that record-breaking weather events tend to have recent dates, but if last year did not break the record it does not mean we have passed a peak.

It is unlikely that any commodity increases in production in a perfectly smooth way. Any change in technology or socio-political context might cause a blip in the rate, which says nothing about where it might ultimately reach a limit. However, this study records it as a peak year. The authors claim that their bootstrap sampling system and cubic spline curve fitting focuses on overall trends rather than blips, but in reality it is no more than an elaborate way to home in on the inflection points in the time course. Was the dip in dairy production around 1990 due to the collapse of the Soviet block or Europe's move from dairy subsidies to land set-asides, or maybe both? The paper records the peakrate year for dairy just before it, and the peak-rate year for milk in the rebound phase after it. Both are artifacts of the dip. Neither says where the ultimate limit of production might be.

Global population growth is a case in point. We had a record increment in 1989, as the paper notes, but we have also had an increasing increment (rebound) since 2000, possibly peaking about now but not necessarily committing to a downward trend from here, and certainly saying little about the ultimate peak population. The 1989 peak was related to the huge increase in child survival in the 1950s and 1960s (a step-change in medical technology and transnational aid), followed by fertility decline resulting from the pill and family planning roll-out (a step-change in contraceptive technology and national population policy), causing a generational bulge in the number of mothers. There was always going to be another bulge on the shoulder of that peak, as the grandchildren of the postwar baby boom were born, but because of the suppression of family planning, that shoulder has turned into another peak. There is nothing mathematically consistent about this course. It is about the timing of changes in technologies and policies.

The paper would have us believe that scarcity of fossil fuels and phosphate are the least of our worries, being among the few resources not to have peaked yet. However, we know from many capable estimates of remaining resources that these peaks are soon (Mohr et al. 2015), and they are absolute peaks in production, not high-points in production growth.

We are certainly reaching critical issues of planetary boundaries (Turner 2008, Clugston 2012, Steffen et al. 2015). However, we have not passed the peak of food production in the sense assumed by the media reports who took up this paper. It is this sort of distracting analysis, methodologically impenetrable to most readers, that prevents society from formulating a clear understanding of what our threats really are.

Responses to this article can be read online at: http://www.ecologyandsociety.org/issues/responses. $\mathrm{php} / 7579$

\section{LITERATURE CITED}

Clugston, C. O. 2012. Scarcity: humanity's final chapter. Booklocker, Port Charlotte, Florida. ISBN 978-1-62141-250-2.

Mohr, S. H., J. Wang, G. Ellem, J. Ward, and D. Giurco. 2015. Projection of world fossil fuels by country. Fuel 141:120-135. http://dx.doi.org/10.1016/j.fuel.2014.10.030

Nature Research Highlights. 2014. Resource use peaks worldwide. Nature 517:246-247. http://dx.doi.org/10.1038/517246e

Seppelt, R., A. M. Manceur, J. Liu, E. P. Fenichel, and S. Klotz. 2014. Synchronized peak-rate years of global resources use. Ecology and Society 19(4): 50. http://dx.doi.org/10.5751/ ES-07039-190450

Steffen, W., K. Richardson, J. Rockström, S. E. Cornell, I. Fetzer, E. M. Bennett, R. Biggs, S. R. Carpenter, W. de Vries, C. A. de Wit, C. Folke, D. Gerten, J. Heinke, G. M. Mace, L. M. Persson, V. Ramanathan, B. Reyers, and S. Sörlin. 2015. Planetary boundaries: guiding human development on a changing planet Science 347(6223). http://dx.doi.org/10.1126/science.1259855

Turner, G. M. 2008. A comparison of The Limits to Growth with 30 years of reality. Global Environmental Change 18:397-411. http://dx.doi.org/10.1016/j.gloenvcha.2008.05.001 